\title{
Photocatalytic Activity of Titanate Nanotube Powders in a Hybrid Pollution Control System
}

\author{
Sun-Jae Kim, ${ }^{1}$ Young-Seak Lee, ${ }^{2}$ Byung Hoon Kim, ${ }^{3}$ Seong-Gyu Seo, ${ }^{4}$ \\ Sung Hoon Park, ${ }^{5}$ and Sang Chul Jung ${ }^{5}$ \\ ${ }^{1}$ Faculty of Nanotechnology and Advanced Materials Engineering, Sejong University, Seoul 143-747, Republic of Korea \\ ${ }^{2}$ Department of Fine Chemical Engineering and Applied Chemistry, Chungnam National University, \\ Daejeon 305-764, Republic of Korea \\ ${ }^{3}$ Department of Dental Materials, School of Dentistry, Chosun University, Gwangju 501-759, Republic of Korea \\ ${ }^{4}$ Department of Civil and Environmental Engineering, Chonnam National University, Yosu 550-749, Republic of Korea \\ ${ }^{5}$ Department of Environmental Engineering, Sunchon National University, Sunchon 540-742, Republic of Korea
}

Correspondence should be addressed to Sang Chul Jung, jsc@sunchon.ac.kr

Received 26 January 2012; Revised 21 February 2012; Accepted 24 February 2012

Academic Editor: Weifeng Yao

Copyright ( 2012 Sun-Jae Kim et al. This is an open access article distributed under the Creative Commons Attribution License, which permits unrestricted use, distribution, and reproduction in any medium, provided the original work is properly cited.

\begin{abstract}
The photocatalytic activity on decomposition of Rhodamine B (RB) of titanate nanotubes (TNTs) synthesized by alkali hydrothermal treatment method was evaluated using a microwave/UV/photocatalyst hybrid system. The effects of each element technique as well as the synergy effects on decomposition of organic material were investigated. When TNTs were ion-exchanged with $\mathrm{HCl}$, $\mathrm{Na}^{+}$content was reduced from $8.36 \mathrm{wt} \%$ to $0.03 \mathrm{wt} \%$, whereas the TNTs calcined at $723 \mathrm{~K}$ was phase-transformed into anatase structure. The RB decomposition rate increased with TNTs dosage as well as with microwave intensity. Effect of addition of auxiliary oxidants on photocatalytic decomposition of RB was also investigated. When ozone was added, the decomposition rate increased with the amount of ozone added. When $\mathrm{H}_{2} \mathrm{O}_{2}$ was used as the auxiliary oxidant, however, addition of $\mathrm{H}_{2} \mathrm{O}_{2}$ exceeding a threshold amount caused reduction of decomposition rate. A synergy effect was observed when $\mathrm{H}_{2} \mathrm{O}_{2}$ addition was combined with microwave-assisted photocatalysis.
\end{abstract}

\section{Introduction}

Titanate nanotube (TNT), having unique properties, for example, tubular structure, large surface area, strong ion exchange, and high sedimentation rate, is a material with high potential in various applications such as supports, ion exchange, adsorption, and dye sensitized solar cells. Among others, application as photocatalyst is of special interest because of its material property combined with nanoscale structure. Nevertheless, data reported for the photocatalytic activity of synthesized TNTs are inconsistent. According to Yu et al. [1], who used TNT synthesized hydrothermally at $423 \mathrm{~K}$ with $48 \mathrm{~h}$ of treatment time to enhance the photocatalytic oxidation of acetone in air, TNT showed no photocatalytic activity before calcination. It has been reported that nanotubes do not have photocatalytic activity towards amaranth degradation regardless of its sodium content.
Yu et al. [2] synthesized hydrogen titanate nanowires at various heat treatment temperatures and investigated their phase structure, crystallite size, morphology, specific surface area, pore structure, and photocatalytic activity. Baiju et al. [3] investigated the photocatalytic activity of a mixed nanobeltsnanotubes titanate obtained through hydrothermal method at $423 \mathrm{~K}$ with $30 \mathrm{~h}$ of treating time on degradation of methylene blue. They reported that photocatalytic activity of the catalyst was very low although it exhibited high adsorptivity towards methylene blue. On the other hand, Nakahira et al. [4] reported a significantly high activity of TNT on degradation of $\mathrm{HCHO}$ under UV light. Xiao et al. [5] also found that TNT synthesized hydrothermally at $403 \mathrm{~K}$ with $24 \mathrm{~h}$ of treating time had a high photocatalytic activity on degradation of Rhodamine B (referred to as RB hereafter), with the degradation efficiency similar to that of P25. This inconsistency found in the literature may be attributed, at 
least partly, to different precursors used (amorphous $\mathrm{TiO}_{2}$, anatase, rutile, and their mixture) and reaction conditions applied (temperature and time). Another possibility is that the produced TNT may have contained unreacted anatase phase which could have provided unexpected photocatalytic activity.

It is of growing interest to use microwave energy for synthetic organic chemistry because it can accelerate reactions and improve yields and selectivity. Many researchers have reported improved photocatalytic performance achieved by microwave irradiation. For example, Kataoka et al. [6] reported that microwave irradiation increased the photocatalytic oxidation rate of ethylene by $83.9 \%$. Horikoshi et al. [7] found from their experiments using electron spin resonance (ESR) that generation of $\mathrm{OH}$ radicals during photocatalytic reaction was enhanced by about $20 \%$ by microwave irradiation. One difficulty in combining UV light source and microwave irradiation is electrode spoilage. This problem can be solved if microwave electrodeless lamp is used as the light source. Furthermore, microwave electrodeless lamp brings additional benefits: good photochemical efficiency, long lifetime, low cost, and simple equipment setup [8]. Horikoshi et al. [9] argued that photocatalysis with electrodeless lamp (a double quartz cylindrical plasma photoreactor) was about 10-times more efficient than the photocatalysis using traditional lamp.

In a previous study of ours, the TNTs were calcined at several different temperatures and their photocatalytic activities were compared with those of Degussa P-25 powders [10]. The TNT calcined at $673 \mathrm{~K}$ showed a lower activity than P25 , whereas the activity of the TNT calcined at $698 \mathrm{~K}$ was similar to that of P-25. On the other hand, all the TNTs calcined at $723 \mathrm{~K}$ or higher exhibited higher photocatalytic activities than P-25. In this study, the photocatalytic activity of the TNT calcined at $723 \mathrm{~K}$ was evaluated using a novel microwave/UV/photocatalyst hybrid system. A microwaveassisted electrodeless lamp is used as the UV source. The effect of microwave irradiation on photocatalytic reaction efficiency is investigated. To improve the pollutant removal rate further, two auxiliary oxidants, $\mathrm{O}_{3}$ and $\mathrm{H}_{2} \mathrm{O}_{2}$, are added in the reaction and their effects on the reaction efficiency are investigated based on the experimental results. The role of each element technique and interaction among them are discussed.

\section{Experimental}

Commercial $\mathrm{TiO}_{2}$ P25 (Evonik, former Degussa, Germany), composed of $75 \%$ of anatase and $25 \%$ of rutile, was used as raw material for TNT production. The BET surface area and the anatase crystallite size of P25 are about $50 \mathrm{~m}^{2} / \mathrm{g}$ and $25 \mathrm{~nm}$, respectively. P25 was put into a Teflon-lined autoclave containing $10-\mathrm{M} \mathrm{NaOH}$. The suspension was treated ultrasonically for $1 \mathrm{~h}$ to have $\mathrm{TiO}_{2}$ particles dispersed well. Then the autoclave was heated to maintain the temperature at $423 \mathrm{~K}$ for $48 \mathrm{~h}$. After the reaction was completed, nanotube precipitate with a high $\mathrm{pH}$ level was washed repeatedly using distilled water to remove $\mathrm{NaOH}$. The washed precipitate had $8.36 \mathrm{wt} \%$ of $\mathrm{Na}^{+}$at $\mathrm{pH}=7.0$.
It was then again dispersed in 0.1-N HCI solution at $333 \mathrm{~K}$ and stirred for a long time to allow $\mathrm{Na}^{+}$ions trapped on the surface and interior of the particles during the hydrothermal reaction to be ion-exchanged with $\mathrm{H}^{+}$and then removed. During the ion-exchange processing, precipitate was sampled to measure the $\mathrm{Na}^{+}$content. It was confirmed by the analysis of the precipitate that the $\mathrm{Na}^{+}$content of the precipitate was $0.03 \mathrm{wt} \%$ at $\mathrm{pH}=7.0$. The precipitate sample was dried for $24 \mathrm{~h}$ using a freeze-dryer to remove moisture from the sample. The ion-exchanged nanotubes were calcined in air at $723 \mathrm{~K}$ for $30 \mathrm{~min}$ and then were ground in an agate mortar before being used in the photocatalytic experiments. Scanning electron microscope (S4700, Hitachi) and transmission electron microscope (JEM2010F, JEOL) observations showed that the powders had nanotubular shape. The $\mathrm{Na}^{+}$ion content was analyzed by EDX (Oxford INCA energy detector, equipped with SEM). Crystal structure of the powder was analyzed using Xray diffractometer (D/MAX-2500/PC, Rigaku) and ambient Raman Spectroscopy (inVia Raman macroscope, Renishow).

Photocatalytic activity of TNT prepared in this way on decomposition of RB in its aqueous solution was evaluated using a microwave/UV/photocatalyst hybrid process system. RB (Junsei Chem. Co., Ltd.) was chosen because it is not adsorbed well on TNT powders. Refer to our previous paper [11] for detailed description on the experimental apparatus. Microwave irradiation was created by a microwave/UV system manufactured by Korea microwave instrument Co., Ltd. It is composed of a microwave generator (frequency, $2.45 \mathrm{GHz}$; maximal power, $1 \mathrm{~kW}$ ), a three-stub tuner, a power monitor, and a reaction cavity. Microwave (actual power used, 200 600 W) irradiated on the RB aqueous solution $\left(5.0 \times 10^{-6} \mathrm{mM}, 1 \mathrm{~L}\right)$ containing TNT powders (loading, $0.05 \sim 0.15 \mathrm{~g}$ ) was delivered through a wave guide. Microwave irradiation was continuous and its intensity was controlled by a power monitor. Optimal low reflection of the microwave radiation was achieved using the three-stub tuner. The UV source and the microwave generator were located on the right-hand and left-hand sides, respectively, of the device. A stirrer was installed on the back side in the reaction cavity to enhance the microwave transfer.

A double-tube type microwave discharge electrodeless lamp (referred to as MDEL hereafter), with $170 \mathrm{~mm}$ length, $44 \mathrm{~mm}$ inner diameter, and $60 \mathrm{~mm}$ outer diameter, emitting UV upon irradiation of microwave was used in this study. It was made of quartz to maximize the reaction efficiency. Small amount of mercury was doped between the tubes inside the double-tube UV lamp that was kept vacuumed. The lamp used in this study is UV-C type lamp although a little amount of UV-A and UV-B wavelength lights is emitted as well.

Because microwave irradiation heats up the reactant solution, the reaction temperature could not be maintained at a constant without a cooling system. Therefore, the reactant solution was put in a stainless steel beaker installed in a constant-temperature equipment. The heated reactant solution was circulated through a cooling system by a roller pump to keep the reaction temperature constant at $298 \mathrm{~K}$. To investigate the effect of addition of auxiliary oxidants on the decomposition organic compounds, ozone and hydrogen 


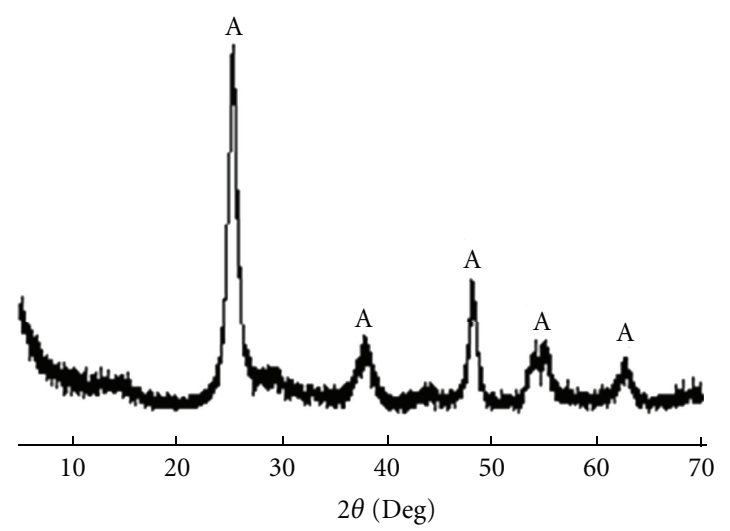

A: anatase

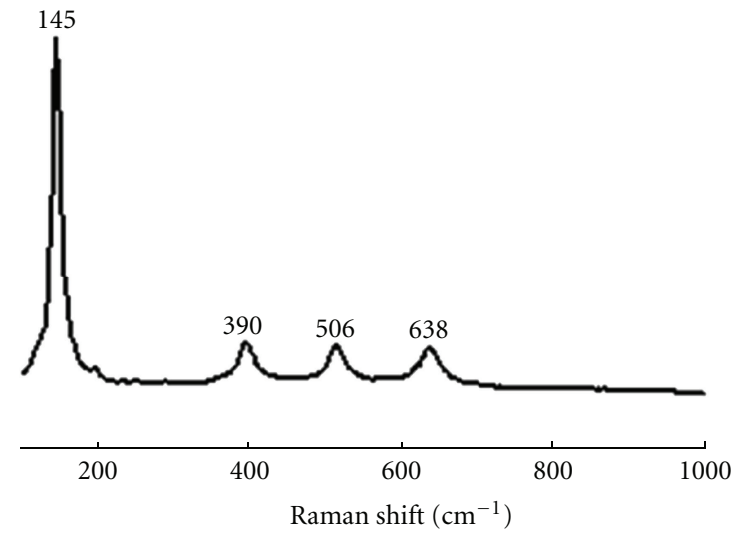

(b)

Figure 1: X-ray diffraction pattern (a) and Raman spectra (b) of TNT powders calcined for 30 min at $723 \mathrm{~K}_{\text {in }} \mathrm{O}_{2}$ atmosphere.

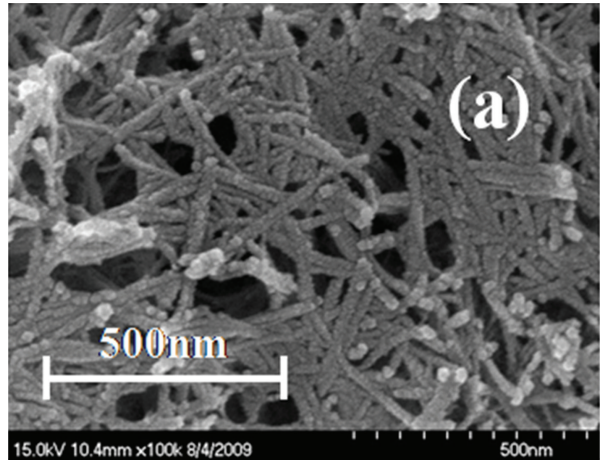

(a)

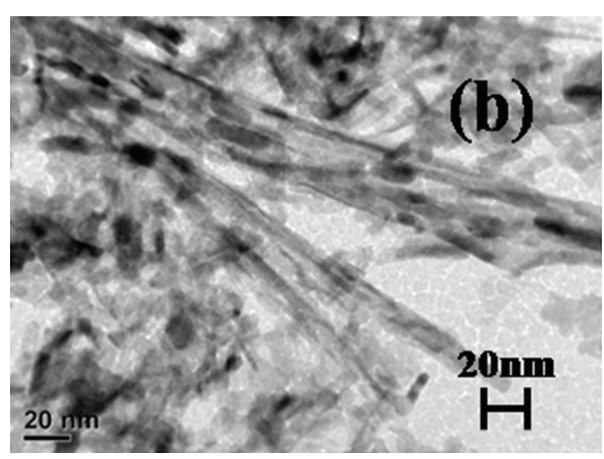

(b)

Figure 2: SEM and TEM images of TNT powders calcined for $30 \mathrm{~min}$ at $723 \mathrm{~K}_{\text {in }} \mathrm{O}_{2}$ atmosphere.

peroxide were added. Ozone was produced by feeding oxygen with the flow rate of $500 \mathrm{cc} / \mathrm{min}$ to an ozone generator (Lab1, Ozone Tech Co., Ltd). The ozone production rate was controlled between 0.75 and $3.26 \mathrm{~g} / \mathrm{hr}$. The reactant solution was prepared using double distilled water. The decomposition rate of $\mathrm{RB}$ was calculated from the change in its concentration measured at the reactor outlet as a function of reaction time. The RB concentration was determined by measuring absorbance at $550 \mathrm{~nm}$ using a spectrophotometer (UV-1601, Shimadzu).

\section{Results and Discussion}

Figure 1(a) shows the XRD results for TNT powders calcined at $723 \mathrm{~K}$ for $30 \mathrm{~min}$ in $\mathrm{O}_{2}$ atmosphere. Characteristic peaks of anatase $\mathrm{TiO}_{2}$ phase at $2 \theta=25.35,37.84,48.14,53.97$, and $55.18^{\circ}$ are clearly observed due to transformation of the titanate into anatase phase. This is in good agreement with Raman spectra shown in Figure 1(b) that demonstrates anatase characteristic peaks at $145,390,506$, and $638 \mathrm{~cm}^{-1}$. It is clearly shown in Figure 1 that the titanate phase transformation was almost complete at $723 \mathrm{~K}$ although trace of the titanate phase was detected at $280 \mathrm{~cm}^{-1}$, which is not clearly shown in normal scale.

Figure 2(a) shows an SEM image of calcined TNT powders. The powders are shown to be nanotubes growing along axial direction. The tubular shape of the powder is observed from a TEM image as well (Figure 2(b)). It is also observed that the powders were broken into nanorods and then became nanoparticles. Figure 2 shows that thermal treatment for 30 minutes at $723 \mathrm{~K}$ in $\mathrm{O}_{2}$ atmosphere did not destroy the nanotubular structure of TNT.

Figure 3 shows the decay in RB concentration obtained with three different TNT powder dosages. For all experiments, initial concentration of RB was about $5.0 \times 10^{-6} \mathrm{mM}$ and $1 \mathrm{~L}$ of solution was circulated into the reactor with a flow rate of $400 \mathrm{cc} / \mathrm{min}$. The intensity of microwave irradiation was $0.4 \mathrm{~kW}$. It is shown that the RB decomposition rate increases with TNT powder dosage. The results for the three cases were all fitted well by linear lines indicating that decomposition of RB over TNT catalyst can be approximated by a pseudo-first-order reaction model:

$$
\frac{C}{C_{0}}=\exp (-K t),
$$




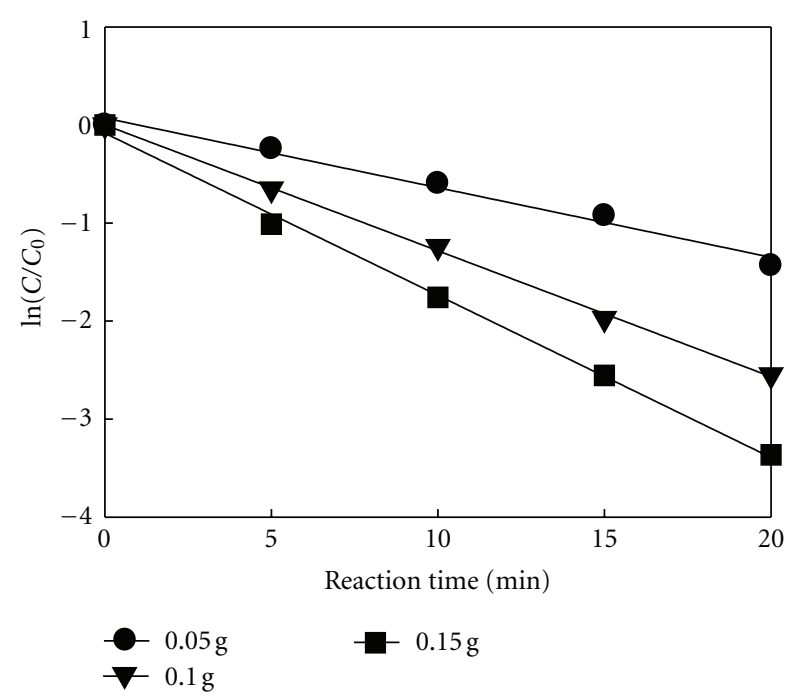

FIgURE 3: Effect of TNT powder dosages on decomposition of RB.

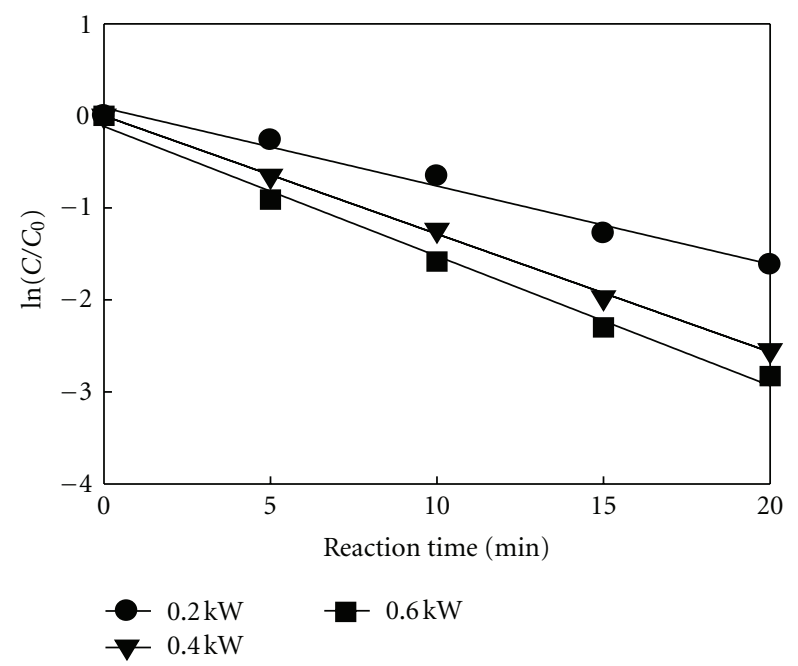

FIGURE 4: Effect of microwave intensity on photocatalytic degradation of RB.

where $C$ is the $\mathrm{RB}$ concentration, $C_{0}$ the initial concentration, $K$ the over-all reaction rate constant, and $t$ the reaction time. $K$ is determined from the slope of the lines shown in Figure 3.

Figure 4 compares the RB concentration decay obtained with three different microwave intensities: $0.2,0.4$, and $0.6 \mathrm{kw}$. For all experiments shown in this figure, $0.1 \mathrm{~g}$ of TNT powders was used. It is clearly shown in this figure that the degradation rate increases with microwave intensity. Microwave irradiation contributes to enhancing the pollutant degradation rate in two ways [7]. It increases temperature selectively, quickly, and uniformly leading to higher reaction rate (thermal effect). Microwave also increases the collision frequency between reactants (nonthermal effect). In addition, microwave intensity affects UV intensity as well in this study because the UV irradiation was created by MDEL upon the irradiation of microwave: higher microwave

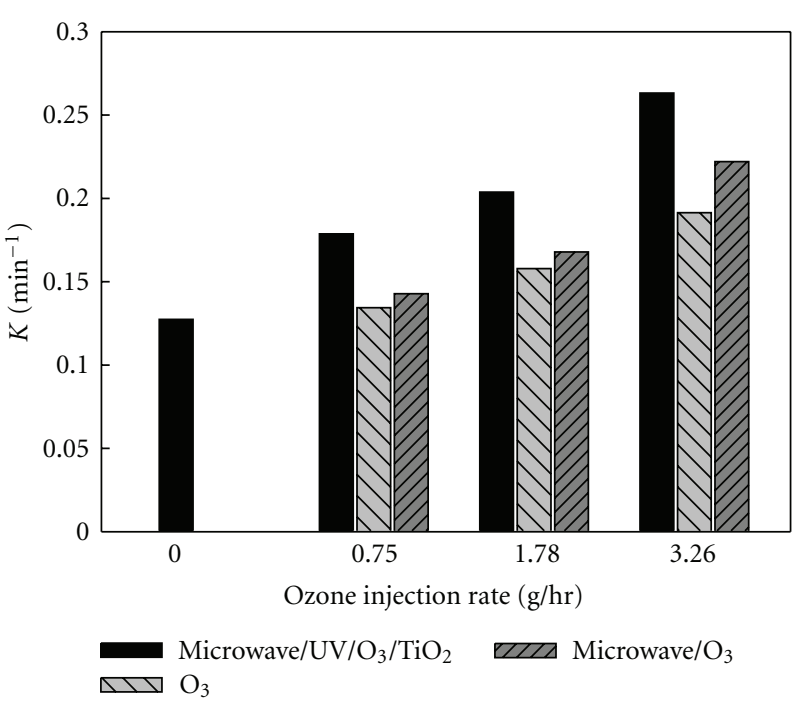

Figure 5: Effect of ozone injection on decomposition of RB.

intensity results in a higher UV intensity. UV, which carries intense energy, enhances the photocatalytic reaction rate by exciting photo-catalyst. Therefore, it was not possible to identify the mechanism by which microwave irradiation contributed to enhancing the photocatalytic reaction rate in this study. It can be either one of the effects described above or combination of two or all of them.

Ozone is a strong oxidant with the electric potential difference of $2.07 \mathrm{~V}$. It has widely been used in water treatment because it can effectively remove taste, odor and precursors of trihalomethanes (THMs). The effect of ozone in oxidation of organic compounds is, however, relatively selective because ozone has very low reactivity on singlebond chemicals and aromatic compounds with specific functional groups such as $-\mathrm{COOH}$ and $-\mathrm{NO}_{2}$. On the contrary, the hydroxyl radical $(\mathrm{OH})$, which has a higher oxidation potential $(2.80 \mathrm{~V})$ than ozone, can react with organic compounds unselectively. Large attention has been given to the advanced oxidation processes (AOPs), in which the organic compounds decomposition is enhanced by $\mathrm{OH}$ radicals. One of the strengths of the microwave/ $\mathrm{UV} / \mathrm{TiO}_{2}$ hybrid system used in this study is that combined microwave and UV irradiations activate photo-catalyst to maximize the formation of $\mathrm{OH}$ radicals when ozone is introduced.

Figure 5 compares the reaction rate constants obtained with three different combinations of element techniques, that is, ozone injection only, ozone injection combined with microwave irradiation, and ozone injection combined with microwave-assisted UV photocatalysis, with four different ozone injection levels: $0,0.75,1.78$, and $3.26 \mathrm{~g} / \mathrm{hr}$. For all the experiments shown in this figure, TNT powder dosage and microwave irradiation intensity were $0.1 \mathrm{~g}$ and $0.4 \mathrm{~kW}$, respectively, when they were applied.

The RB decomposition rate was highest when ozone was injected to the microwave/UV/ $/ \mathrm{TiO}_{2}$ photocatalyst system. The reaction rate increased with ozone dosage. Even the ozone-only experiments showed high RB decomposition rate 


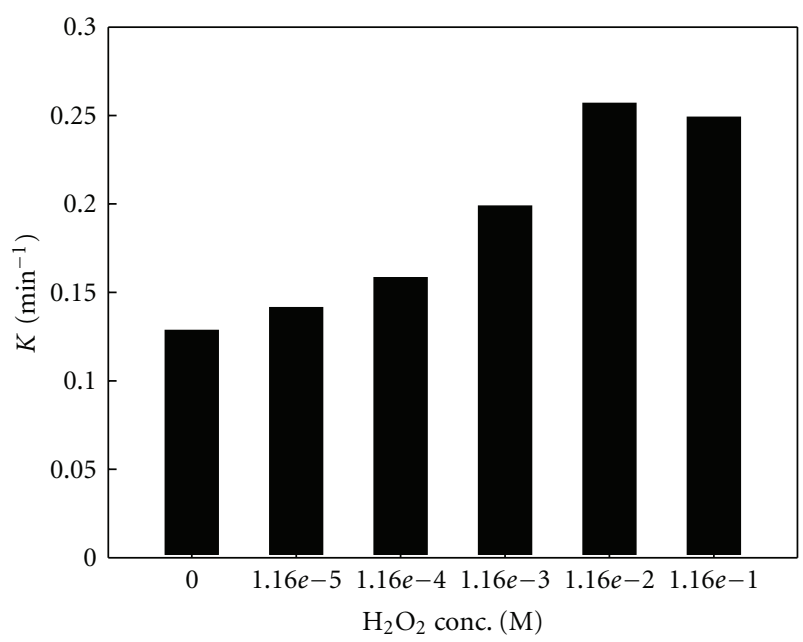

Figure 6: Effect of injection $\mathrm{H}_{2} \mathrm{O}_{2}$ for decomposition of $\mathrm{RB}$ in aqueous solutions.

with the rate constant of 0.1354 , which was a little higher than that obtained by microwave/UV/TiO 2 photocatalyst system without ozone injection (0.1284). When microwave irradiation combined with ozone injection was used, the reaction rate constant was in between the results of the other two conditions. When only microwave irradiation was used, very little RB decomposition was obtained (not shown).

Reports on the effect of $\mathrm{H}_{2} \mathrm{O}_{2}$ on pollutant removal are abundant in the literature. There is a general consensus that addition of $\mathrm{H}_{2} \mathrm{O}_{2}$ enhances the photocatalytic degradation of organic pollutants [12]. The increased reaction rate caused by $\mathrm{H}_{2} \mathrm{O}_{2}$ addition can be explained by a couple of reasons. First, it takes surface-trapped electrons, and hence reduces the electron-hole recombination rate and makes more holes available for reactions creating $\mathrm{OH}$ radicals (e.g., $\mathrm{OH}^{-}+$ $\mathrm{h}^{+} \rightarrow \mathrm{OH}$ ). Second, $\mathrm{H}_{2} \mathrm{O}_{2}$ may split into two $\mathrm{OH}$ radicals directly by photocatalytic reaction. Because $\mathrm{H}_{2} \mathrm{O}_{2}$ can be an efficient electron acceptor in $\mathrm{TiO}_{2}$ photocatalytic systems, its effect on photocatalytic pollutant degradation was evaluated [13]. Figure 6 compares the reaction rate constants obtained with different amount of $\mathrm{H}_{2} \mathrm{O}_{2}$ added to the microwaveassisted photocatalytic system. $\mathrm{H}_{2} \mathrm{O}_{2}$ addition increased the reaction rate while the added amount was smaller than a threshold value, $1.16 \times 10^{-2}$ here, but further addition of $\mathrm{H}_{2} \mathrm{O}_{2}$ exceeding the threshold reduced the reaction rate. This is in good agreement with the results reported in the literature [14] $\mathrm{H}_{2} \mathrm{O}_{2}$ is known to form a surface complex on $\mathrm{TiO}_{2}$ [15], which can cause blocking of surface sites of catalysts if the amount of $\mathrm{H}_{2} \mathrm{O}_{2}$ is too large. Another possible reason for the reduction of photocatalytic reaction rate due to excessive $\mathrm{H}_{2} \mathrm{O}_{2}$ is $\mathrm{OH}$ radical scavenging by $\mathrm{H}_{2} \mathrm{O}_{2}\left(\mathrm{H}_{2} \mathrm{O}_{2}+\right.$ $\mathrm{OH} \rightarrow \mathrm{HO}_{2}+\mathrm{H}_{2} \mathrm{O}$ ). In order to examine the function of $\mathrm{H}_{2} \mathrm{O}_{2}$ as the scavenger of $\mathrm{OH}$ radicals, it is required to observe the change in $\mathrm{OH}$ radicals. For instance, Xiang et al. [16] quantitatively measured the hydroxyl radicals produced from various semiconductor photocatalysts contained in aqueous solutions using the photoluminescence technique. Unfortunately, however, quantitative measurement of the

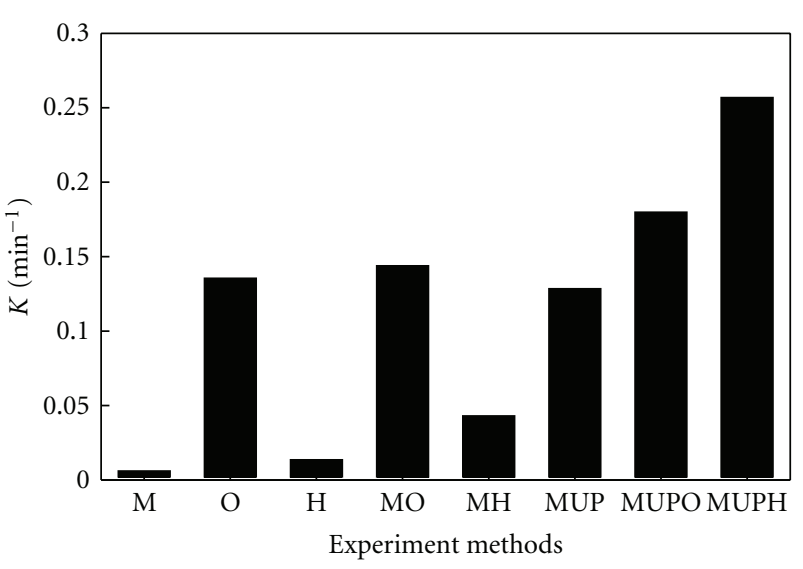

FIGURE 7: Reaction rate constants obtained under various experimental conditions.

hydroxyl radicals was not possible in this study due to the difficulty of installation of a sensor in the microwave cavity.

Figure 7 compares the decomposition rate constants obtained under different experimental conditions. The results of eight different experiments are shown in this figure: microwave irradiation only $(\mathrm{M})$, ozone injection only $(\mathrm{O})$, $\mathrm{H}_{2} \mathrm{O}_{2}$ injection only $(\mathrm{H})$, microwave irradiation combined with ozone injection ( $\mathrm{MO})$, microwave irradiation combined with $\mathrm{H}_{2} \mathrm{O}_{2}$ injection (MH), microwave-assisted photocatalysis by MDEL (MUP), MUP combined with ozone injection (MUPO), and MUP combined with $\mathrm{H}_{2} \mathrm{O}_{2}$ injection (MUPH). For all the experiments shown in this figure, TNT powder dosage of $0.1 \mathrm{~g}$, microwave irradiation intensity of $0.4 \mathrm{~kW}$, circulation flow rate of $400 \mathrm{~mL} / \mathrm{min}$, ozone injection rate of $0.75 \mathrm{~g} / \mathrm{h}$, and $\mathrm{H}_{2} \mathrm{O}_{2}$ addition amount of $1 \mathrm{~mL}$ $\left(1.1632 \times 10^{-2} \mathrm{~mol}\right)$ were used. A relatively low ozone injection rate of $0.75 \mathrm{~g} / \mathrm{h}$ was used because the reaction proceeded too fast under some conditions with a higher ozone injection rate.

As shown in Figure 7, RB was hardly decomposed under $\mathrm{M}(K=0.0060)$ and $\mathrm{H}(K=0.0135)$ conditions. The reaction constant was low also under $\mathrm{MH}$ condition $(K=$ 0.0430). When these element techniques were all combined (MUPH), however, the reaction rate was about six times that obtained under $\mathrm{MH}$ condition $(K=0.2568)$. Completely different results were obtained with addition of ozone. While the reaction rate constants of condition $\mathrm{O}(K=0.1354)$ and condition MO $(K=0.1438)$ were high compared to those obtained with other element techniques, the reaction rate obtained under MUPO in which all these techniques were combined was not very high $(K=0.1798)$ showing no synergy effect.

Microwave, which is an electromagnetic wave with a very short wavelength, excites polar molecules to cause them to rotate and vibrate back and forth rapidly. For example, water molecules can vibrate about $2.45 \times 10^{9}$ times every second upon microwave irradiation. The original objective of this study was to enhance the decomposition reaction rate by exciting pollutant molecules using microwave irradiation. According to the experimental results shown above (M), 
however, the effect of excitement of pollutant molecules was negligible. Nevertheless, when the microwave-assisted photocatalysis was combined with addition of auxiliary oxidant such as $\mathrm{H}_{2} \mathrm{O}_{2}$, a synergy effect enhancing the reaction rate considerably was observed. This result suggests that microwave irradiation may promote the production of active intermediate products, for example, $\mathrm{OH}$ radicals, by exciting the auxiliary oxidant molecules. It should be noted, however, that this hypothesis cannot be proved based only on the limited experimental results of this study. Further studies under different conditions, including different pollutants and different auxiliary oxidants, are required to validate the hypothesis further.

\section{Conclusion}

To use hybrid pollution control system for advanced treatment of RB, a series of experiments were performed in which the effects of microwave irradiation and auxiliary oxidants were evaluated. The conclusions obtained from the experimental results are as follows.

(1) When TNTs was ion-exchanged with $\mathrm{HCl}, \mathrm{Na}^{+}$content was reduced from $8.36 \mathrm{wt} \%$ to $0.03 \mathrm{wt} \%$, whereas the TNTs calcined at $723 \mathrm{~K}$ was phase-transformed into anatase structure.

(2) The RB decomposition rate increased with TNTs dosage as well as with microwave intensity.

(3) When ozone was added, the decomposition rate increased with the amount of ozone added.

(4) When $\mathrm{H}_{2} \mathrm{O}_{2}$ was used as the auxiliary oxidant, however, addition of $\mathrm{H}_{2} \mathrm{O}_{2}$ exceeding a threshold amount caused reduction of decomposition rate.

(5) When the microwave-assisted photocatalysis was combined with addition of auxiliary oxidant such as $\mathrm{H}_{2} \mathrm{O}_{2}$, a synergy effect enhancing the reaction rate considerably was observed.

\section{Acknowledgment}

This research was supported by Basic Science Research Program through the National Research Foundation of Korea (NRF) funded by the Ministry of Education, Science, and Technology (2010-0007412 and 2011-0016699).

\section{References}

[1] J. Yu, H. Yu, B. Cheng, and C. Trapalis, "Effects of calcination temperature on the microstructures and photocatalytic activity of titanate nanotubes," Journal of Molecular Catalysis A, vol. 249, no. 1-2, pp. 135-142, 2006.

[2] H. Yu, J. Yu, and B. Cheng, "Photocatalytic activity of the calcined H-titanate nanowires for photocatalytic oxidation of acetone in air," Chemosphere, vol. 66, no. 11, pp. 2050-2057, 2007.

[3] K. V. Baiju, S. Shukla, S. Biju, M. L. P. Reddy, and K. G. K. Warrier, "Hydrothermal processing of dye-adsorbing one-dimensional hydrogen titanate," Materials Letters, vol. 63, no. 11, pp. 923-926, 2009.
[4] A. Nakahira, W. Kato, M. Tamai, T. Isshiki, and K. Nishio, "Synthesis of nanotube from a layered $\mathrm{H}_{2} \mathrm{Ti}_{4} \mathrm{O}_{9} \cdot \mathrm{H}_{2} \mathrm{O}$ in a hydrothermal treatment using various titania sources," Journal of Materials Science, vol. 39, no. 13, pp. 4239-4245, 2004.

[5] M. W. Xiao, L. S. Wang, X. J. Huang, Y. D. Wu, and Z. Dang, "Synthesis and characterization of $\mathrm{WO}_{3} /$ titanate nanotubes nanocomposite with enhanced photocatalytic properties," Journal of Alloys and Compounds, vol. 470, no. 1-2, pp. 486491, 2009.

[6] S. Kataoka, D. T. Tompkins, W. A. Zeltner, and M. A. Anderson, "Photocatalytic oxidation in the presence of microwave irradiation: observations with ethylene and water," Journal of Photochemistry and Photobiology A, vol. 148, no. 1-3, pp. 323330, 2002.

[7] S. Horikoshi, H. Hidaka, and N. Serpone, "Environmental remediation by an integrated microwave/UV-illumination method. 1. Microwave-assisted degradation of rhodamine-B dye in aqueous $\mathrm{TiO}_{2}$ dispersions," Environmental Science and Technology, vol. 36, no. 6, pp. 1357-1366, 2002.

[8] J. Literak and P. Klan, "The electrodeless discharge lamp: a prospective tool for photochemistry. Part 2. Scope and limitation," Journal of Photochemistry and Photobiology A, vol. 137, no. 1, pp. 29-35, 2000.

[9] S. Horikoshi, H. Hidaka, and N. Serpone, "Environmental remediation by an integrated microwave/UV illumination technique VI. A simple modified domestic microwave oven integrating an electrodeless UV-Vis lamp to photodegrade environmental pollutants in aqueous media," Journal of Photochemistry and Photobiology A, vol. 161, no. 2-3, pp. 221-225, 2004.

[10] N. H. Lee, H. J. Oh, S. C. Jung, W. J. Lee, D. H. Kim, and S. J. Kim, "Photocatalytic properties of nanotubular-shaped $\mathrm{TiO}_{2}$ powders with anatase phase obtained from titanate nanotube powder through various thermal treatments," International Journal of Photoenergy, vol. 2011, Article ID 327821, 7 pages, 2011.

[11] S. H. Park, S. J. Kim, S. G. Seo, and S. C. Jung, "Assessment of microwave $/ \mathrm{UV} / \mathrm{O}_{3}$ in the photo-catalytic degradation of bromothymol blue in aqueous nano $\mathrm{TiO}_{2}$ particles dispersions," Nanoscale Research Letters, vol. 5, no. 10, pp. 1627-1632, 2010.

[12] M. Harir, A. Gaspar, B. Kanawati et al., "Photocatalytic reactions of imazamox at $\mathrm{TiO}_{2}, \mathrm{H}_{2} \mathrm{O}_{2}$ and $\mathrm{TiO}_{2} / \mathrm{H}_{2} \mathrm{O}_{2}$ in water interfaces: kinetic and photoproducts study," Applied Catalysis $B$, vol. 84, no. 3-4, pp. 524-532, 2008.

[13] R. N. Rao and N. Venkateswarlu, "The photocatalytic degradation of amino and nitro substituted stilbenesulfonic acids by $\mathrm{TiO}_{2} / \mathrm{UV}$ and $\mathrm{Fe}^{2+} / \mathrm{H}_{2} \mathrm{O}_{2} / \mathrm{UV}$ under aqueous conditions," Dyes and Pigments, vol. 77, no. 3, pp. 590-597, 2008.

[14] S. Kim, H. Park, and W. Choi, "Comparative study of homogeneous and heterogeneous photocatalytic redox reactions: $\mathrm{PW}_{12} \mathrm{O}_{40}{ }^{-3}$ vs $\mathrm{TiO}_{2}$," Journal of Physical Chemistry B, vol. 108, no. 20, pp. 6402-6411, 2004.

[15] J. Q. Chen, D. Wang, M. X. Zhu, and C. J. Gao, "Photocatalytic degradation of dimethoate using nanosized $\mathrm{TiO}_{2}$ powder," Desalination, vol. 207, no. 1-3, pp. 87-94, 2007.

[16] Q. Xiang, J. Yu, P. K. Wong, and M. Chen, "Facile fabrication of mechanochromic-responsive colloidal crystal films," Journal of Colloid and Interface Science, vol. 357, no. 1, pp. 163-168, 2011. 


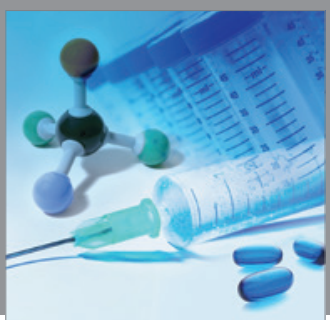

International Journal of

Medicinal Chemistry

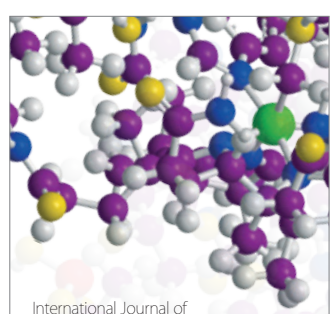

Carbohydrate Chemistry

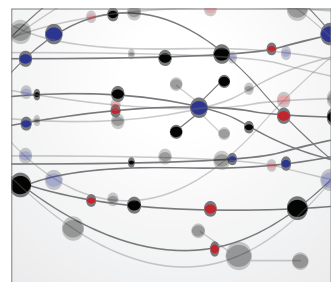

The Scientific World Journal
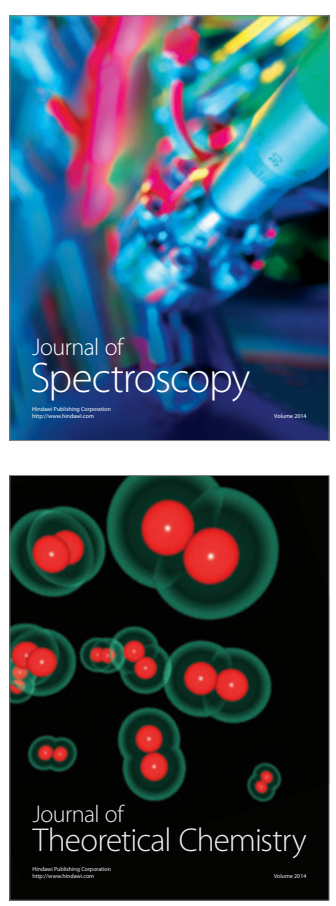
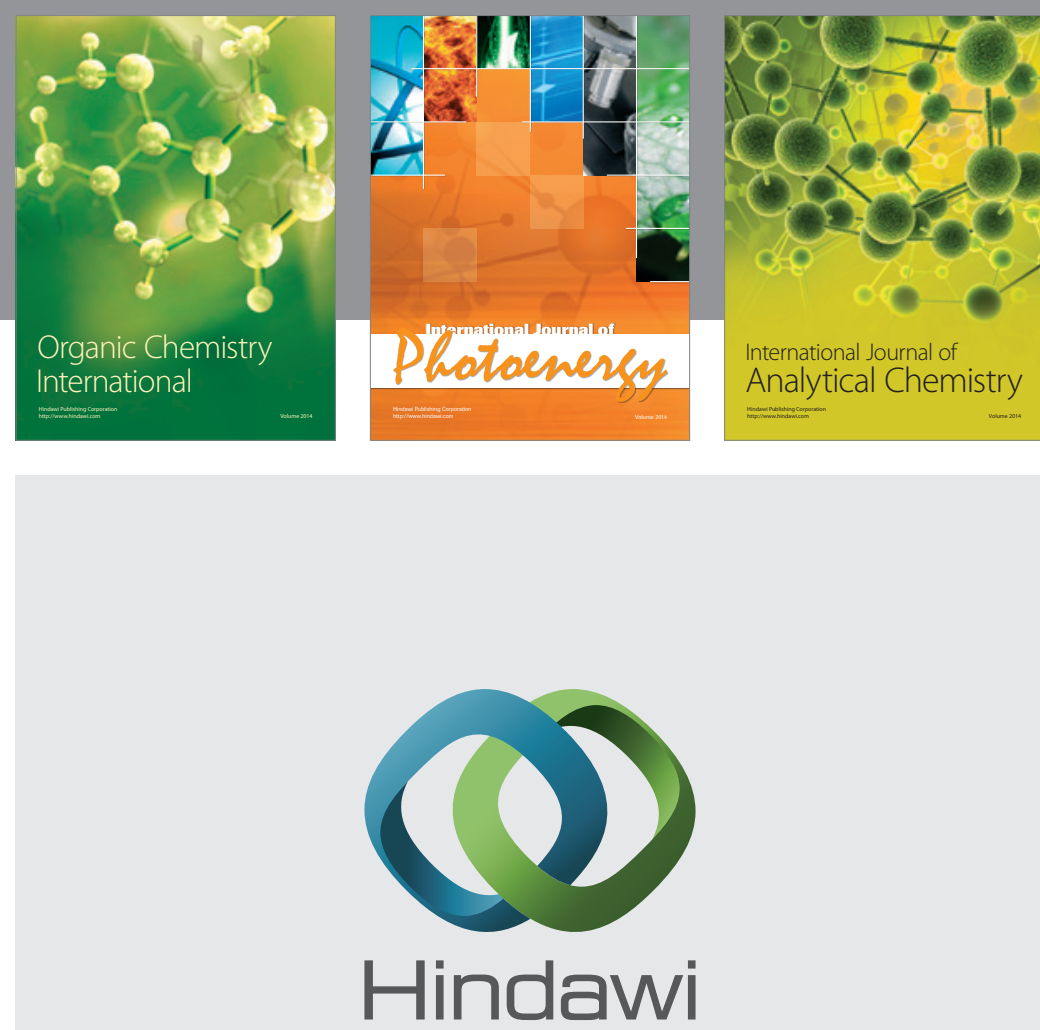

Submit your manuscripts at

http://www.hindawi.com
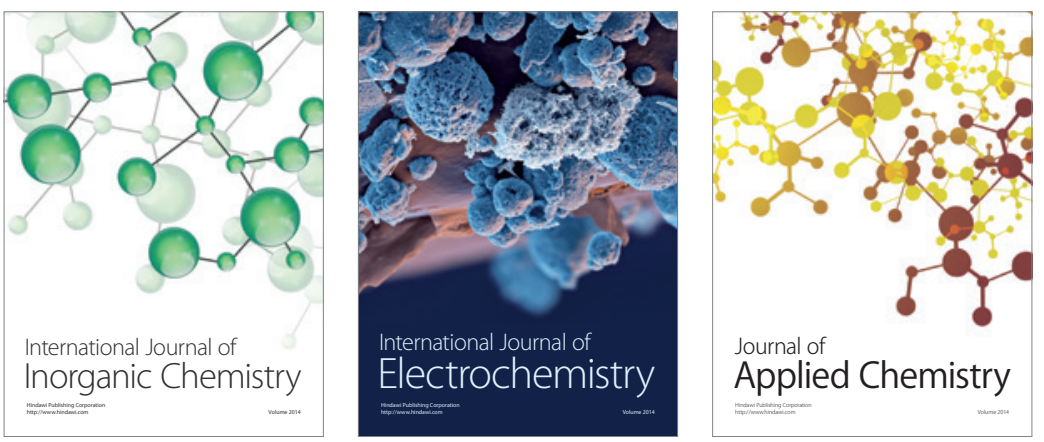

Journal of

Applied Chemistry
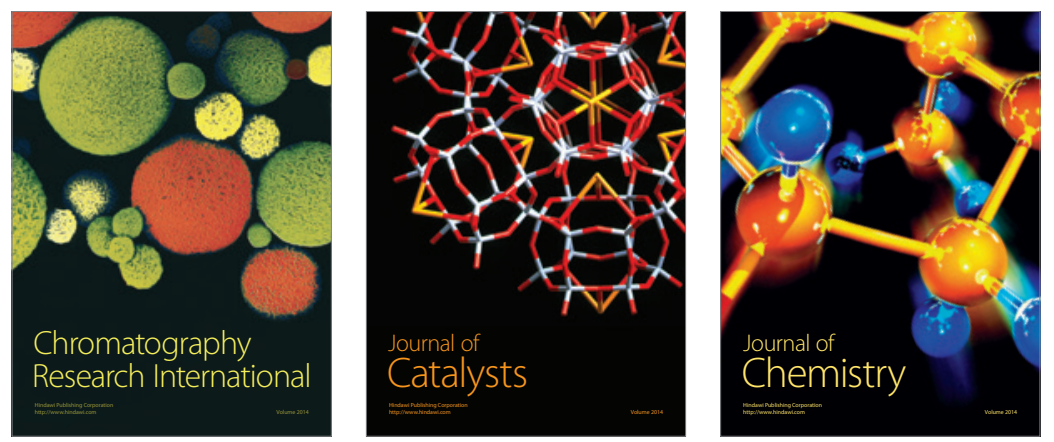
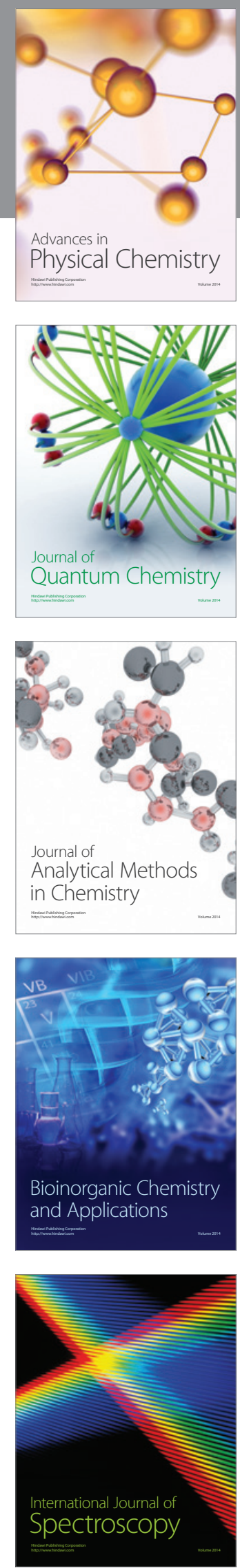